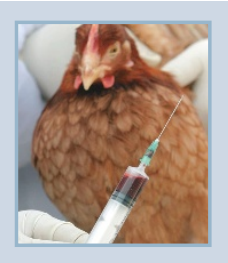

\author{
p214 One flu over \\ Asia: Small steps \\ toward a human \\ vaccine for the \\ avian flu.
}

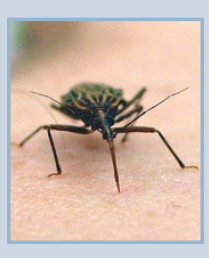

p216 Bugs vs. drugs: Can GM insects succeed where conventional drugs have failed?

\title{
Contraceptive research pregnant with anticipation
}

In 1964, a woman had three choices for contraception: she could take a hormone-based pill, insert a barrier device or convince her partner to wear a condom. A woman in 2004 has the same choices - and they leave much to be desired: pills affect the whole body, barrier devices can fail and condoms are not an option for many women, particularly in the developing world.

The dearth of choices is not for lack of demand. Between 1995 and 2000, there were 300 million unplanned pregnancies worldwide, according to the Global Health Council. The demand will only increase: within the next decade, an unprecedented 600 million women are expected to enter reproductive age.

"If you look at where contraception is now, it's really not much further along than in the 1960 s, when the first hormone pills came out," says Gregory S. Kopf, assistant vice president of Wyeth's Women's Health Research Institute. In male contraceptives, there has not been a breakthrough since the condom, which was first seen in ancient Egypt, Kopf notes. "There's not a whole lot out there."

That could soon change. In January, a US Institute of Medicine (IOM) panel called for scientists to use the powerful tools of genomics and proteomics to create comprehensive lists of the genes, proteins, fats and sugars expressed in sperm and eggs. The goal, the panel said, is to sift through those that are uniquely expressed in those tissues and create a new generation of contraceptives.

Because of the many obstacles-economic, regulatory, political and legal-to contraceptive research, only a handful of companies, including Wyeth, are still invested in the field.

Germany-based Schering, along with Organon, recently began clinical trials on a male contraceptive combining testosterone and progestin, which temporarily turns off the brain signals that stimulate sperm production. The US Food and Drug Administration (FDA) recently approved Seasonale, a new birth control pill that suppresses periods for months at a time. Australian researchers are beginning trials on a spray that transfers Nestorone, a synthetic progestin, across the skin.

Still, most new products continue to be variations on steroid manipulation. "It's sort of the 'same-old, same-old' approach," says John Eppig, a senior staff scientist at The Jackson Laboratory in Bar Harbor, Maine. "I think [the companies] want to change that."

In some laboratories, recent advances in mass spectrometry, two-dimensional gel proteomics and other techniques are helping scientists zero in on molecules responsible for sperm and egg development, fertilization and implantation of fertilized eggs in the uterine lining.

"Like the rest of biomedical science, the field of reproductive science is really in its golden age," Eppig says. "I'm 60-somethingand I've never been more excited about the research going on in my lab and elsewhere."

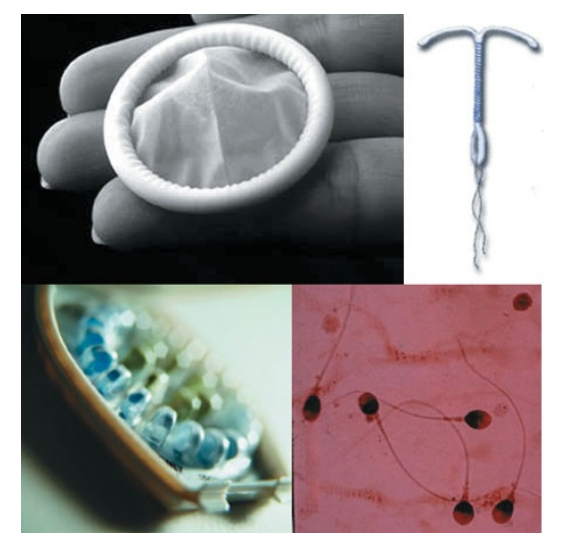

Eppig's team is trying to decipher how eggs talk to the nonreproductive cells surrounding them. "We believe this two-way communication will ultimately yield interesting contraceptive targets," Eppig says. Using microarrays and techniques such as subtractive hybridization and a signal-sequence trap to detect secreted proteins, the team has already found a few egg-specific signals. "We're using just about everything we can think of," says Eppig. "We're throwing the kitchen sink at it."

Eppig also heads a mutagenesis program where researchers are screening hundreds of mouse families for infertility mutations. "This, I believe, is the most interesting approach to contraception you could have," he says.

Some researchers are using DNA microarrays to identify genes selectively expressed in the testis or oocytes. The sperm or egg 'tran- scriptome' can be a powerful tool, says John Herr of the University of Virginia. But because there is more diversity at the protein level, proteomics is a more useful approach, Herr says.

Herr and his colleagues have created 'sperm-check'-the male equivalent of the ovulation kit-to detect and quantify sperm. The device, which can be used to check sperm levels in the weeks after a vasectomy or as a companion to male contraceptives, will be submitted for FDA approval in a few months. Herr has also identified sperm-specific membrane proteins required for sperm-egg fusion. A recombinant sperm vaccine created from five such proteins is being tested in monkeys.

David Garbers' team at the University of Texas Southwestern Medical Center at Dallas is also interested in proteins on the sperm's outer surface, as those proteins are more likely to be involved in important signaling cascades. The researchers have already found several candidates, including an unusual voltage-gated calcium channel crucial for sperm hyperactivation.

As scientists come up with possible new contraceptives, "one has to be thinking almost simultaneously about the method of delivery and the likelihood of acceptance in the target community," says Jerome Strauss III, director of the Center for Research on Reproduction and Women's Health at the University of Pennsylvania. People don't like to take pills every day, notes Strauss, who chaired the IOM panel. But, for instance, a 'smart material' that is liquid at room temperature and forms a gel inside the body could reversibly block fallopian tubes, he says.

To promote interdisciplinary research on such smart materials and maintain a dialogue between basic biologists, product developers, behavioral scientists and funding agencies, the panel recommended the creation of an international alliance for contraceptive research, which would monitor progress in the field.

"We've made more progress in the last two years than we'd made in all the decades before," says Garbers, who also served on the panel. "I think it's going to explode around us in the next 5 or 10 years."

Apoorva Mandavilli, New York 